\title{
Low temperature formation of copper rich silicides
}

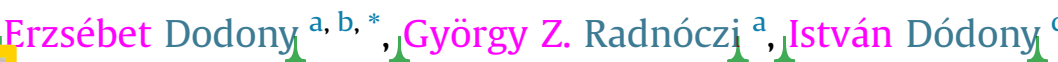

Hungarian Academy of Sciences, Center for Energy Research, Institute of Technical Physics and Material Sciences, Thin Film Physics Laboratory, H-1121,

Budapest, Konkoly-Thege M. út 29-33, Hungary

b Department of Material Physics, Eötvös Loránd University, Pázmány Péter Sétány 1/A, Budapest, H-1117, Hungary

c Department of Mineralogy, Eötvös Loránd University, Pázmány Péter Sétány 1/C, Budapest, H-1117, Hungary

\section{A R T I C L E I N F O}

Article history:

Received 28 November 2018

Received in revised form

4 January 2019

Accepted 8 January 2019

Available online $\mathrm{xxx}$

Keywords:

Copper-silicide

Crystal structure

Modulation

Electron crystallography

\begin{abstract}
A B S T R A C T
The reactions of copper and amorphous silicon were studied by in-situ transmission electron microscopy up to $500^{\circ} \mathrm{C}$. Only the $\mathrm{Cu}_{76} \mathrm{Si}_{24}-\eta$ phase and the $\mathrm{Cu}_{82} \mathrm{Si}_{18}-\delta$ phase formed at this temperature. The crystal structure of the dominating $\mathrm{Cu}_{76} \mathrm{Si}_{24}$ changed, by the elapsed time after heating. The $\mathrm{Cu}-\mathrm{Si}$ ordering resulted in different supercells, built up by topologically identical subcells with different site occupancies and arrangement. Two modulated crystal structures were solved based on diffraction data and HRTEM
\end{abstract} images.

() 2019 Published by Elsevier Ltd.

\section{Introduction}

Copper silicides are being intensively studied, because of their wide range of applications in many fields. $\mathrm{Cu}_{3} \mathrm{Si}$ (also denoted by $\left.\mathrm{Cu}_{76} \mathrm{Si}_{24}, \mathrm{Cu}_{3+\mathrm{x}} \mathrm{Si}, \mathrm{Cu}_{3} \mathrm{Si}_{1-\mathrm{x}}\right)$ is a key ingredient in ultrapure silicon synthesis (99.99999\%) suitable for photovoltaic and electric devices [1]. It is used as contact material in microelectronics and as catalyst in production of semiconductor and carbon nanowires. The thrift of the solar cell production depends on refining metallurgical grade silicon to solar grade silicon [2] and on the lowering of the crystallization temperature of amorphous-Si $(a-S i)$ to crystalline-Si ( $c$ $\mathrm{Si}$ ) in thin layers. The copper rich silicide phases have a great impact on several technical applications, e.g. in Li-ion batteries [3]. In spite of the impact of copper-silicides, their phases and structural relations are still not detailed properly.

In the focus of experimental works and thermodynamic calculations is the phase diagram of the copper-silicon system. The most cited phase diagram of the system is the 1986 work of Olesinski and Abbaschian [4]. Cui and Jung [5] gave a comprehensive overview in the field of the $\mathrm{Cu}-\mathrm{Si}$ system; one can find the relevant literature therein. The phases at the copper rich side of the phase diagram is

* Corresponding author. Hungarian Academy of Sciences, Center for Energy -Research, Institute of Technical Physics and Material Sciences, Thin Film Physics Laboratory, H-1121, Budapest, Konkoly-Thege M. út 29-33, Hungary.

E-mail address: erzsebet.dodony@energia.mta.hu (E. Dodony). the object of our study and it is shown in Fig. 1 (after Cui and Jung [5]). There are many differences between the widely cited phase diagram of Olesinski and Abbaschian and the recent results [5], showing us an uncertainty of the $\mathrm{Cu}-\mathrm{Si}$ phase diagram. A good example for this uncertainty is the work of P. Riani et al. [6] who studied the stability of the $\mathrm{Cu}_{79} \mathrm{Si}_{21}-\varepsilon$ phase.

Many studies have been published on the crystal structures of the copper silicide phases since 1935. Fagerberg and Westgren [7] studied alloys with the structure of $\beta-\mathrm{Mn}$ and found $\mathrm{Cu}_{82} \mathrm{Si}_{18}$ structure to be this type. The first structure model for the $\mathrm{Cu}_{3} \mathrm{Si}_{1-\mathrm{x}}$, so called $\eta$-phase $\left(\mathrm{Cu}_{76} \mathrm{Si}_{24}\right.$ in Fig. 1$)$ was given in 1978 by Solberg [8], who proposed a structure model for the high temperature $\eta$ phase with trigonal symmetry. Additionally, he obtained superstructures - denoted as $\eta^{\prime}$ and $\eta "$ - stable at room temperature. This was in use until Mattern et al. [9 and 10] determined the structure model of $\eta$-phase shown in Fig. 2. Later, Wen and Spaepen [11] interpreted their findings on the copper containing precipitates in silicon crystals the same way as Mattern et al..

They proposed rhombohedral symmetries for $\eta^{\prime}$ and $\eta$ " polymorphs as result of long period antiphase boundaries. Corrêa et al. [12] measured the $\mathrm{Cu}_{3+\mathrm{x}} \mathrm{Si}$ polymorphs by X-ray powder diffraction using copper radiation and established six modifications in this narrow compositional range, although they found all modifications having the similar unit cell. Palatinus et al. [13] using their SUPERFLIP software [14] implemented in JANA2006 [15] interpreted their data on $\eta$ phases having incommensurate structure. 


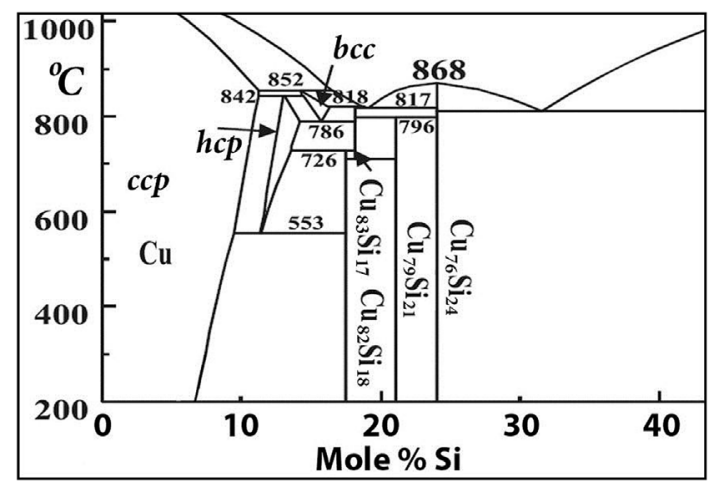

Fig. 1. Phase diagram of the $\mathrm{Cu}-\mathrm{Si}$ system (after [5]).

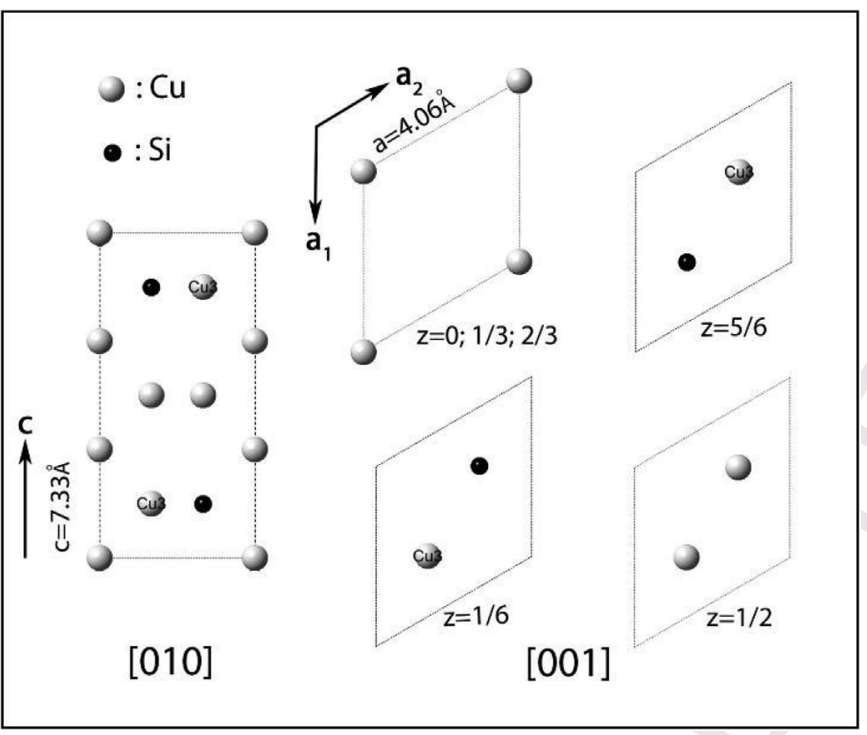

Fig. 2. Structure model of $\mathrm{Cu}_{3+\mathrm{x}} \mathrm{Si}-\eta$ in [010] projection and cross sections along $\mathrm{z}$ direction in [001] projection as described by Mattern et al. and Wen and Spaepen [9,10 and 11].

However, these long period and incommensurate structures were not confirmed as separate thermodynamic phases [4]. The $\mathrm{Cu}-\mathrm{Si}$ phases in the ICSD2017 data base [16] are listed in Table 1.

We performed in-situ transmission electron microscopic (TEM) experiments on phase formations of $\mathrm{Cu}$ - Si upon heating. We measured the cooled down samples after the heat treatment at room temperature using TEM. Selected area electron-diffraction patterns (SAED) served as basis of phase identifications, whereas high resolution images revealed the $\mathrm{Cu} / \mathrm{Si}$ ordering. The experimental diffraction patterns and high resolution images, confirmed the atomic positions of $\mathrm{Cu}_{76} \mathrm{Si}_{24}$ [11] basic structure of Mattern et al.
$[9,10]$ and Wen \& Spaepen [11], with different site occupancies.

\section{Material and methods}

\subsection{Sample preparation}

The applied starting materials were copper TEM grids (SPI, \#200) covered by $10 \mathrm{~nm}$ thick amorphous silicon ( $a-\mathrm{Si}$ ) film. The silicon films were magnetron sputtered on a turntable under argon atmosphere of $3 \times 10^{-3} \mathrm{mbar}(300 \mathrm{~W}, 672 \mathrm{~V}, 0.454 \mathrm{~A}$ without bias) to $\mathrm{NaCl}$ substrate and transferred to the $\mathrm{Cu}$ grid through water baths.

A side-entry Philips PW 6599 heating stage attached with a Pt/ PtRh thermocouple powered by a Philips PW 6363/00 regulating unit was used in a Philips CM20 microscope. The precision of the temperature measurement of the sample holder in this setup is $\pm 15^{\circ} \mathrm{C}$ at the location of the thermocouple. The temperature was increased from room temperature to $350^{\circ} \mathrm{C}$ in $6 \mathrm{~min}$ and subsequently by $50^{\circ} \mathrm{C}$ increment with waiting time in between the steps, to $500^{\circ} \mathrm{C}$. At this temperature, solid state reaction began between the contacted a-Si thin film and Cu grid. The temperature was held at this temperature for $48 \mathrm{~min}$, while the reactions carried on leaving copper-silicide phases behind. The heating was turned off, when the area covered with a-Si in the inspected grid window seemed almost fully reacted leaving a small area of unreacted $a-\mathrm{Si}$ in the middle and samples were let to cool down to room temperature in vacuum.

\subsection{Applied methods}

During the heating we followed the progress of copper silicide phase formation based on their appearance in bright field imaging using a Philips CM20 microscope.

The ex-situ observations were carried out in Philips CM20 and JEOL JEM 3010 type transmission electron microscopes (TEMs) equipped with double-tilt sample holders. Images and SAED patterns were recorded on imaging plates (CM20) and with $2 \times 2 \mathrm{k} 2$ bytes CCD camera (JEOL 3010). The symmetry and lattice parameters identify reaction products were measured on their SAED patterns. Sample thickness was deduced from SAED patterns also, using the measurable resolution maxima values after Cowley [17]. The high resolution (HRTEM) images were acquired using the JEOL TEM.

We used selected area electron diffraction (SAED) patterns for phase identification. The high-resolution images helped to determine structural relations between coexisting phases. The strong electron-matter interaction requires to handle multiple scattering in the function of sample thickness for evaluation of experimental SAED and HRTEM data [18]. Knowing optical parameters of the applied microscope (accelerating voltage, spherical aberration and stability) and its experimental settings (defocus value, aperture size, beam divergence) provide a reliable basis for comparison of experimental and simulated data. The beam divergence can be

Table 1

The known crystal structures in the $\mathrm{Cu}-\mathrm{Si}$ system.

\begin{tabular}{|c|c|c|c|c|}
\hline Composition & Sign in Fig. 1 & Reference & ICSD\#. & Prefix \\
\hline $\mathrm{Cu}_{15} \mathrm{Si}_{4}$ & $\mathrm{Cu}_{79} \mathrm{Si}_{21}$ & Mukherjee et al. (1969) [26] & 629165 & $\varepsilon$ \\
\hline $\mathrm{Cu}_{3.17} \mathrm{Si}$ & $\mathrm{Cu}_{76} \mathrm{Si}_{24}$ & $\begin{array}{l}\text { Wen and Spaepen (2007) [11] } \\
\text { Mattern et al. }(2001,2007)[9,10]\end{array}$ & 160694 & $\eta$ and $\eta^{\prime \prime}$ \\
\hline $\mathrm{Cu}_{0.83} \mathrm{Si}_{0.17}$ & $\mathrm{Cu}_{82} \mathrm{Si}_{18}$ & Fagerberg and Westgren (1935) [7] & 52285 & $\delta$ \\
\hline $\mathrm{Cu}_{0.875} \mathrm{Si}_{0.125}$ & hcp & Foley and Raynor (1961) [27] & 108407 & $\kappa$ \\
\hline $\mathrm{Cu}$ & bcc & $\begin{array}{l}\text { Xie et al. (2011) [28] } \\
\text { Jona and Marcus (2001) [29] }\end{array}$ & $\begin{array}{l}183263 \\
248435\end{array}$ & $\begin{array}{l}\beta \\
\beta^{\prime}\end{array}$ \\
\hline
\end{tabular}


determined from the size of reflections acquired at the same conditions as the corresponding HRTEM image or by examining the dampening function of the HRTEM images. The parameter was previously determined for the used microscopes. The defocus value could be obtained on the Fourier transform of an HRTEM image from the contrast transfer function's first crossover position [18]. Both the SAED patterns and HRTEM images were compared to their corresponding simulated counterparts calculated by Cerius ${ }^{2} 4.0$ software (Molecular Simulation Institute, Inc.). CRISP (Calidris, Version 2.1a) and Digital Micrograph 2.30.542.0 software packages served for image processing, simulations and quantification of diffraction data. In CRISP Fourier filtering was done by inverse Fourier transform using phases and amplitudes at the local maxima of the Fourier transform preformed on an HRTEM image (lattice averaging [18]).

\section{Results and discussion}

The initial stage of reaction between the copper grid and $a-\mathrm{Si}$ is represented by Fig. 3. All of our experimental data are combination of signals from the reaction products between the copper grid and the $10 \mathrm{~nm}$ thick $a$-Si layer and the unreacted amorphous silicon layer (a-Si) underneath. We know after Re et al. [19] that overlapping an amorphous layer reduces aesthetic quality of both

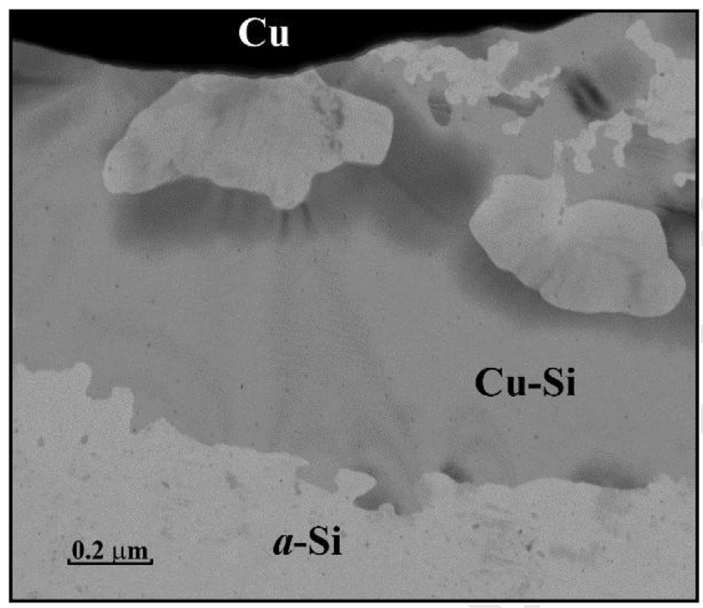

Fig. 3. Image of the reaction products between copper grid bars and amorphous silicon (a-Si) in a Philips CM20 microscope film after the 8th minute at $500^{\circ} \mathrm{C}$.
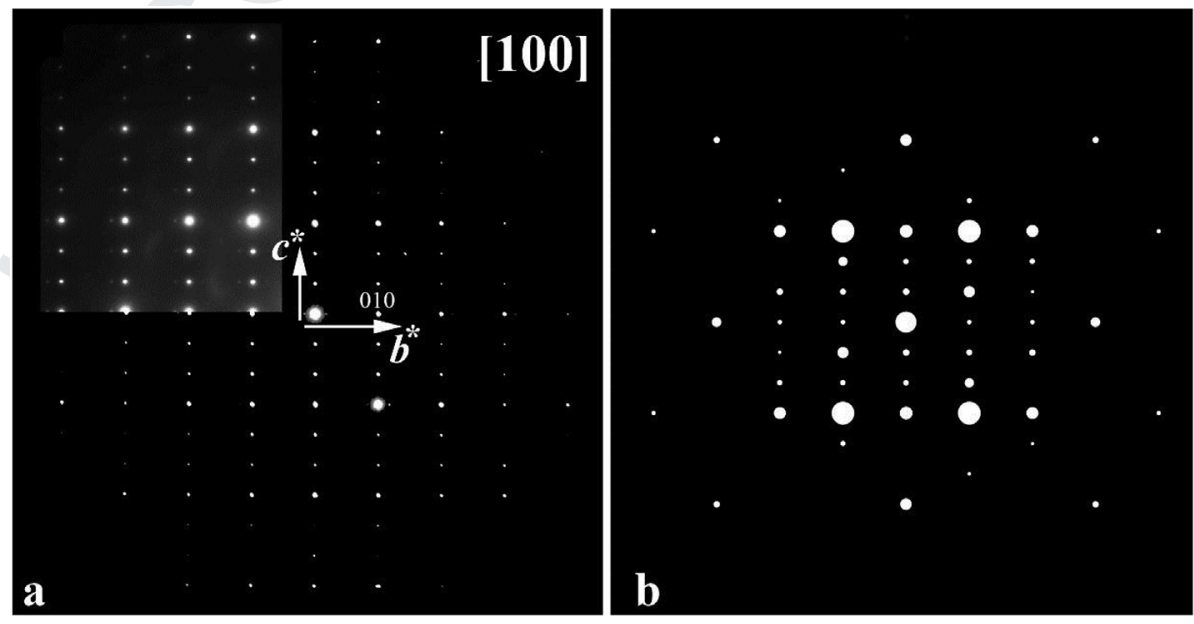

Fig. 4. Experimental (a) and simulated (b) SAED pattern (Wen and Spaepen's data) of $\mathrm{Cu}_{76} \mathrm{Si}_{24}-\eta$. Their different intensity distributions are evident.

HRTEM images and SAED patterns, however structural data can still be retrieved from these. The thickness measured on SAED patterns (using the formula of Cowley [17]) usually varied in between $60 \AA$ and $80 \AA$. For instance, if the $\eta$-phase is $80 \AA$ thick, then it only consumes an $18 \AA$ thick layer of a-Si. The amorphous part blurs significantly the HRTEM images of the tarnishing crystalline phases [19]. The background intensities in the SAED patterns are clouded by the $a-\mathrm{Si}$ as it is shown below in the upper left corner of Fig. $4 \mathrm{a}$.

\subsection{The $\mathrm{Cu}_{82} \mathrm{Si}_{18}-\delta$ phase}

The beta-manganese analog copper rich silicide $(\delta)$ phase [7] is a minor component of the reaction products of $a$-Si and the supporting Cu-grid. Fig. 5 and Fig. 6 demonstrate the defect free crystal structure of $\mathrm{Cu}_{82} \mathrm{Si}_{18}$ by its SAED and HRTEM images. The weak satellite reflections seen near the reflections of the tetragonal net, originate from misoriented grains of the same phase close to the selected area. The $P 4_{1}{ }_{1} 2$ space group of $\mathrm{Cu}_{82} \mathrm{Si}_{18}$ only allows $h=4 n$ type reflections for $h 00$. The $h \neq 4 n$ type reflections in the observed SAED patterns and Fourier-transforms of HRTEM images are due to dynamical scattering.

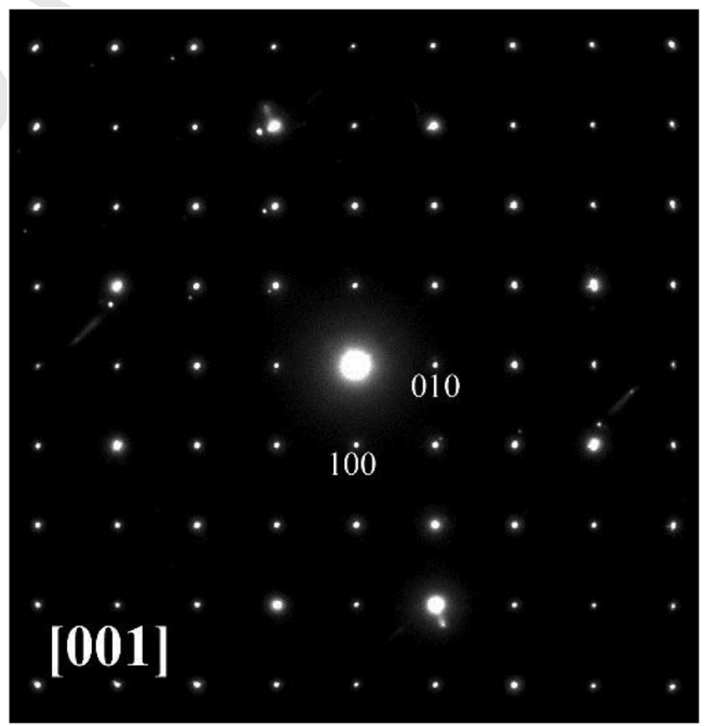

Fig. 5. SAED pattern of a $\delta$-phase crystallite $\left(\mathrm{Cu}_{82} \mathrm{Si}_{18}\right)$. 


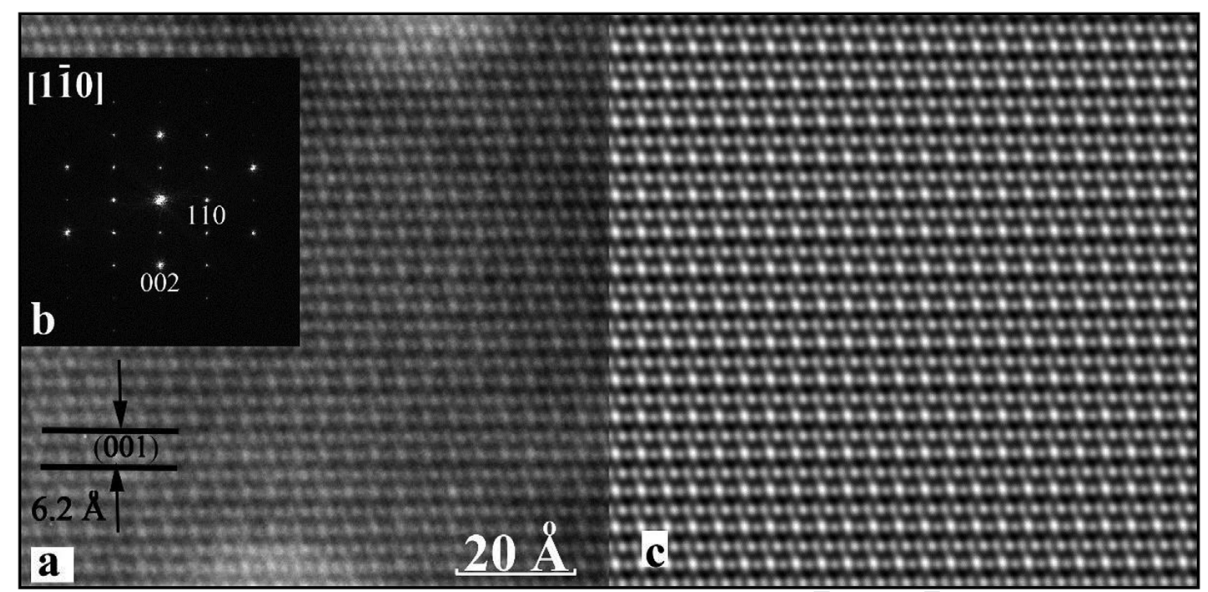

Fig. 6. Raw experimental HRTEM image of $\mathrm{Cu}_{82} \mathrm{Si}_{18}$ crystal (a), its Fourier-transform (b) and the Fourier-filtered experimental image (c).

\subsection{The $\mathrm{Cu}_{76} \mathrm{Si}_{24}$ - $\eta$ phase}

The $\mathrm{Cu}_{76} \mathrm{Si}_{24}-\eta$ phase [9,10 and 11] (Fig. 2.) - also denoted by $\mathrm{Cu}_{3} \mathrm{Si}, \mathrm{Cu}_{3+\mathrm{x}} \mathrm{Si}, \mathrm{Cu}_{3} \mathrm{Si}_{1-\mathrm{x}}$ - is the dominant component of the reaction product between $\mathrm{Cu}$ grid and $a$-Si film as revealed by SAED patterns. The observed $d_{h k l}$ values match well with the simulated

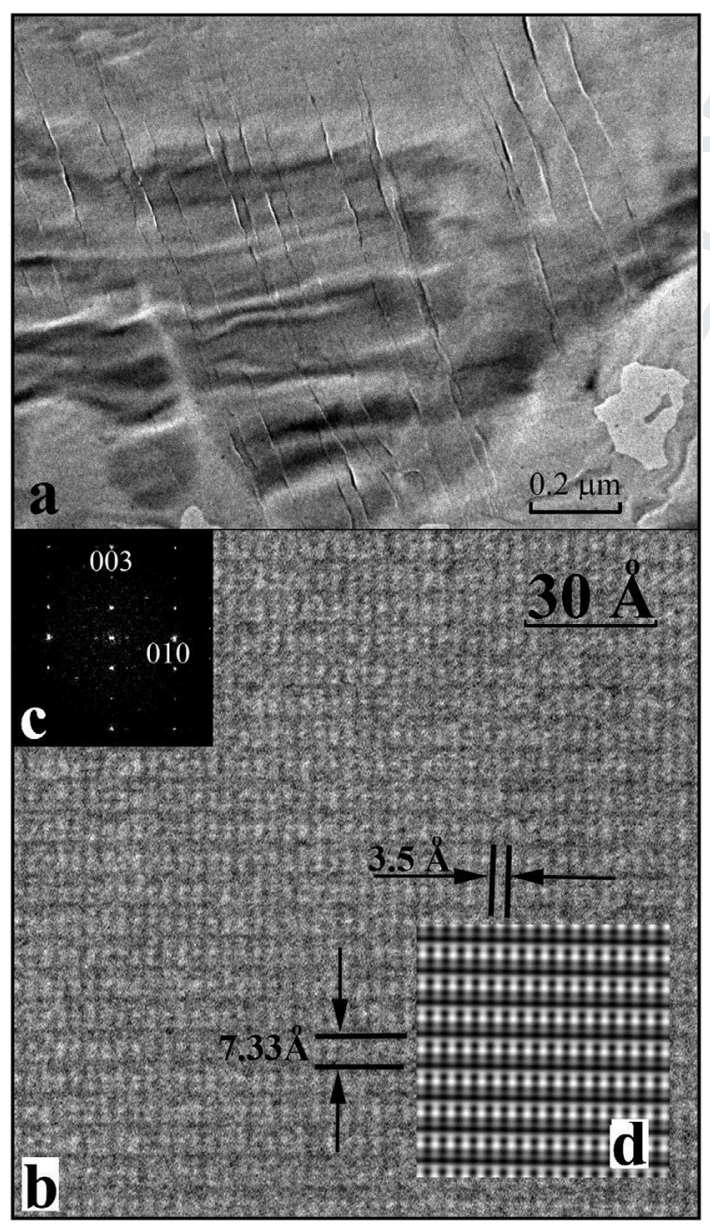

Fig. 7. (a) Bright field TEM image of a lamellar $\mathrm{Cu}_{76} \mathrm{Si}_{24}$ area close to the [100] projection, (b) raw experimental HRTEM image of $\mathrm{Cu}_{76} \mathrm{Si}_{24}$, (c) its Fourier-transform and (d) the Fourier-filtered and symmetry imposed (pm plane group)) experimental image. ones based on the Wen and Spaepen (2007) data as it is shown in Fig. 4. However, the experimental and simulated intensities deviate from each other. There is lack of the point symmetry relations in the experimental pattern of the $\eta$ phase [9,10 and 11]; the calculated intensities of the $0 \mathrm{kl}$ and $0 \bar{k} l$ are different. As a consequence, a revised structure model is needed to describe the $\mathrm{Cu}_{3} \mathrm{Si}$ phase.

The lamellar texture of an area of $\mathrm{Cu}_{76} \mathrm{Si}_{24}$ in orientation close to [100] is visible in Fig. 7. The HRTEM image on a selected lamella and its Fourier-transform in Figs.6ab is conform to the SAED pattern shown in Fig. 4a. The intense 010 maximum is evident in both figures. The noisy Fourier transform reflects the low contrast in the experimental HRTEM image.

We compared our experimental data to the corresponding simulated data, based on the Wen and Spaepen [10] structure model of the $\eta$-phase. The results showed poor match both for the SAED as well as for HRTEM images. The dynamical SAED simulations were performed in the Cerius $^{2}$ package $(200 \mathrm{kV}$, sample thickness: $81 \AA$ ). Fig. 8 demonstrates a drastic difference in the

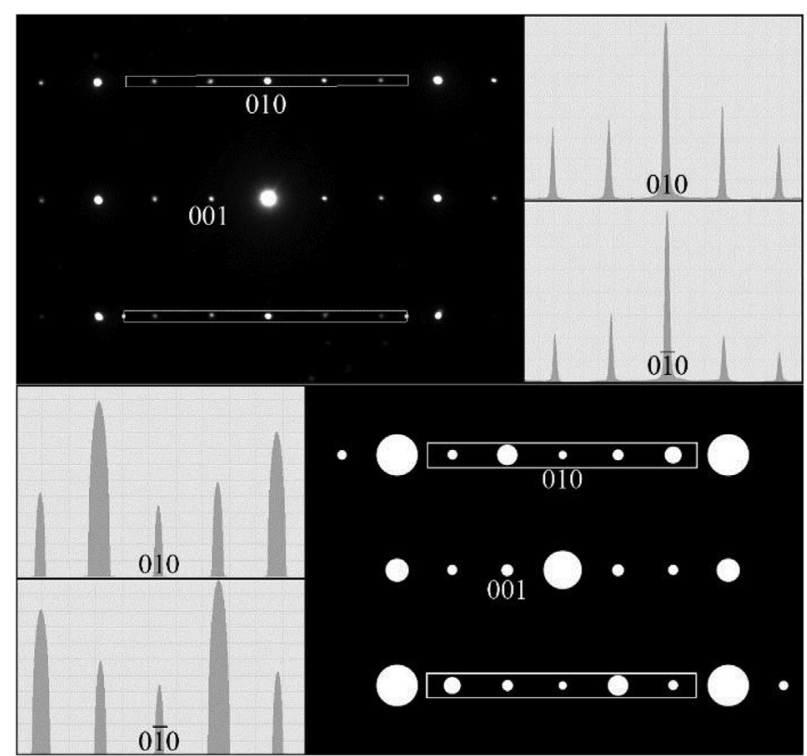

Fig. 8. Diffracted intensity distributions integrated by Digital Micrograph along the stripes for the experimental (in the upper half) and the corresponding calculated one (in the bottom half) using the Wen and Spaepen's data. Differences between the two sets are significant.
66

67

68

69

70

71

72

73

74

75

76

77

78

79

80

81

82

83

84

85

86

87

88

89

90

91

92

93

94

95

96

97

98

99

100

101

102

103

104

105

106

108

109

110

111

112

114

\section{5}

117

118 


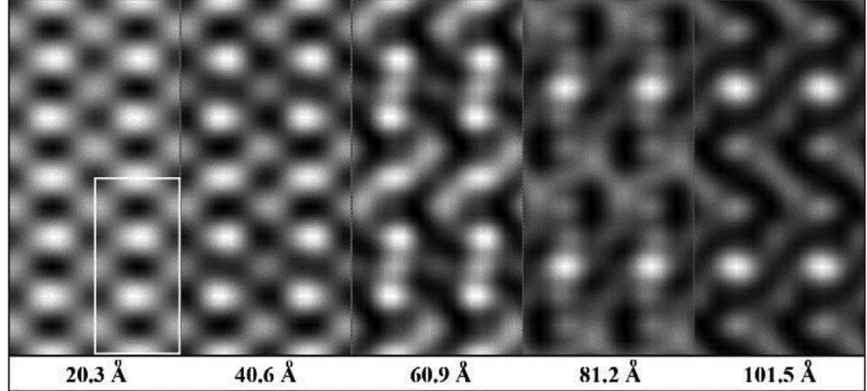

Fig. 9. Wen and Spaepen's data based simulated [100] HRTEM images in the function of the sample thickness. There was no observed HRTEM image showing satisfactory match with any simulated one.

Table 2

Occupancies and atomic coordinates for the modified $\mathrm{Cu}_{3} \mathrm{Si}$ structure; space group: $P-3 m 1, a_{0}: 4.06 \AA, c_{0}: 7.33 \AA$.

\begin{tabular}{lllll}
\hline$\#$ & Occupancy & $\mathrm{x}$ & $\mathrm{y}$ & $\mathrm{z}$ \\
\hline 1 & Cu 1.000 & 0.0000 & 0.0000 & 0.0000 \\
2 & Cu 0.500 & 0.6667 & 0.3333 & 0.1667 \\
3 & Si 1.000 & 0.3333 & 0.6667 & 0.1667 \\
4 & Cu 1.000 & 0.0000 & 0.0000 & 0.3333 \\
5 & Cu 1.000 & 0.6667 & 0.3333 & 0.5000 \\
6 & Cu 1.000 & 0.3333 & 0.6667 & 0.5000 \\
7 & Cu 1.000 & 0.0000 & 0.0000 & 0.6667 \\
8 & Si 1.000 & 0.6667 & 0.3333 & 0.8333 \\
9 & Cu 0.500 & 0.3333 & 0.6667 & 0.8333 \\
\hline
\end{tabular}

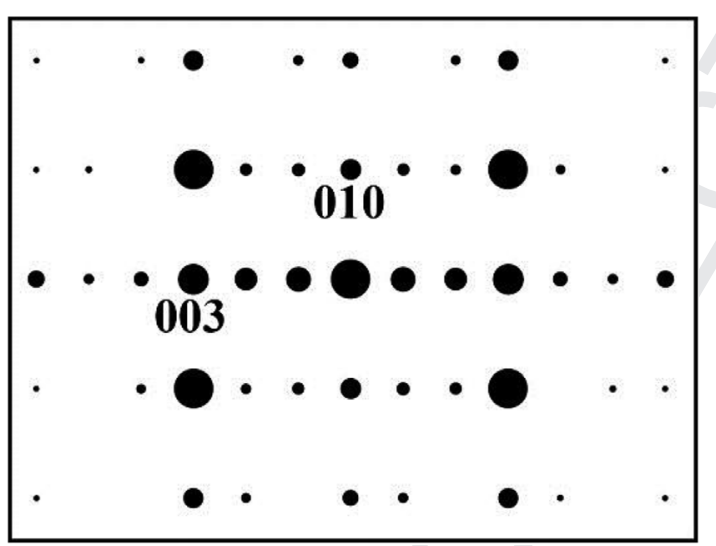

Fig. 10. Calculated [100] projected SAED pattern of the modified Wen and Spaepen's model with matching intensities as in the experimental pattern shown in Fig. 8. intensity distributions of [100] projected crystal. The differences in intensity ratios are far above the tolerance that could be explained by sample thickness or misorientation, which was checked in Cerius $^{2} 4.0$ software package.

HRTEM many-beam multi-slice calculations $\left(300 \mathrm{kV} ; c_{s}\right.$ : $0.6 \mathrm{~mm}$; defocus spread $40 \AA ̊$; extended Schertzer defocus $\Delta f:-400 \AA$ ) were carried out as a function of sample thickness on the [100] projected Wen and Spaepen [10] structure model. The applied defocus value was measured as described in section 2.2 (practically, there was no astigmatism). The result is shown in Fig. 9. Surprisingly there is no experimental HRTEM image showing similar contrast to any of the simulated image, especially close to the real sample thickness. (The sample thickness was measured on SAED patterns, by applying the $t=2 d_{\text {res }}^{2} / \lambda$ formula $[17,18]$.) Due to the poor match of the experimental and simulated data some serious doubts have arisen about the validity of the structure model used hitherto.

To resolve the problem, we built several structure models for unmodulated and stoichiometric $\eta-\mathrm{Cu}_{3} \mathrm{Si}$, varying site occupancies in the original [9,10 and 11] model (Fig. 2). Changes in values of the site occupation factors of the two $\mathrm{Cu} 3$ (at $1 / 3,2 / 3,1 / 6$ and $2 / 3,1 / 3$, $5 / 6$ coordinates) to 0.5 and the rest to 1 , result in a structural model (Table 2) satisfying appropriate matches to the experimental SAED pattern and HRTEM images. Electron crystallography software CRISP [18] - served as a good tool to recover projected charge density (PCD) using HRTEM image and diffracted intensities in the corresponding SAED pattern. Fig. 10 shows a simulated [100] projected SAED pattern for $81 \AA$ sample thickness using the new, modified Wen and Spaepen basic structure for $\mathrm{Cu}_{3} \mathrm{Si}$. Comparing to the experimental SAED pattern in Fig. 8a the fit is satisfactory. A PCD map (Fig. 11c) was generated from the raw experimental HRTEM image in Fig. 11a using electron crystallographic methods implemented in CRISP. We validated our modified Wen and Spaepen [10] structural model by comparing the simulated PCD map to the one recovered from the experimental data is shown in Fig. 11c; the result is presented in Fig. 12. The PCD map at $1.82 \AA$ resolution (Fig. 12b) and the image - based on the experimental HRTEM image - in Figs. 11 and 12c fits well. Cu3 and Si positions are marked by circle and square respectively in the insert in Fig. 12a.

Most of the $\mathrm{Cu}_{76} \mathrm{Si}_{24}$ grains have modulated structures in directions along and perpendicular to the [001] direction. An HRTEM image and its FFT in Fig. 13 show a doubled periodicity (14.66 A) along the $\boldsymbol{c}$ axis. Fig. 14 shows the modulation along the $\mathbf{a}^{*}$, the periodicity is four times of the basic $d_{010} \approx 3.5 \AA$.

In previous works, it was stated that the modifications (so called $\eta^{\prime}, \eta ", \ldots$ polymorphs) differ from each other not only by periodicities along the main crystallographic directions, but also in their
66

67

68

69

70

71

72

73

74

75

76

77

78

79

80

81

82

83

84

85

86

87

88

89

90

91

92

93

94

95

96

97

98

99

100

101

102

103

104

105

106

107

108

109

110

111

112

Fig. 11. Raw HRTEM image (a), its Fourier-transform (b) and PCD map (c) generated from (a) using electron crystallographic methods implemented in CRISP package. 


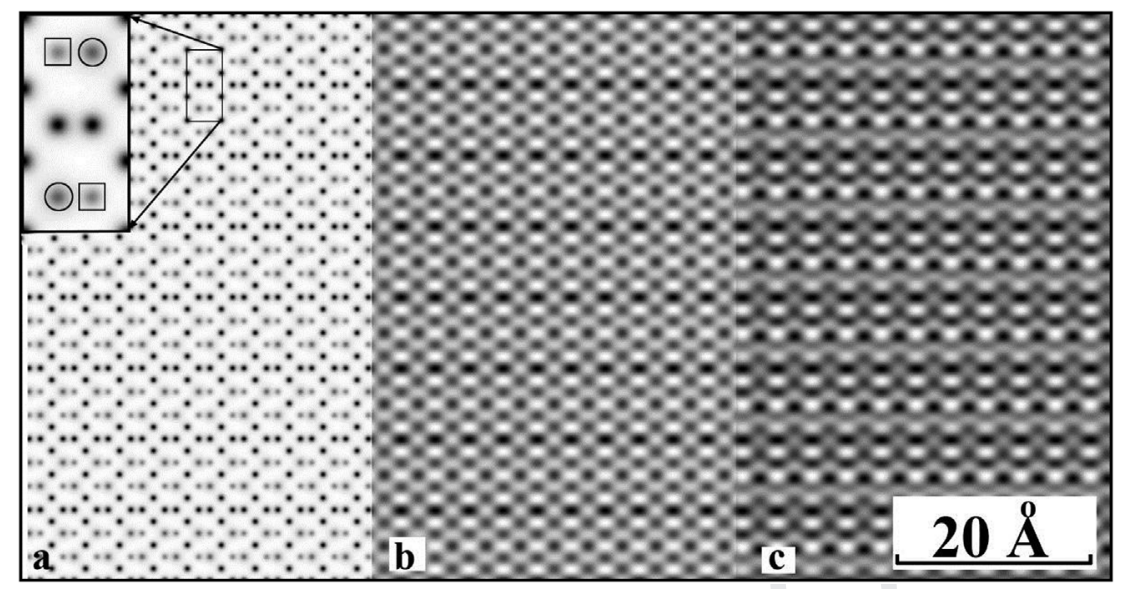

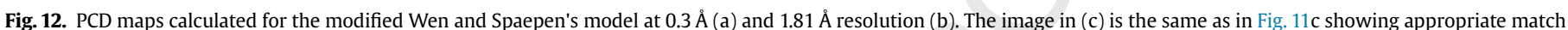
to image in (b). The insert in (a) indicates the unit cell where circles are at $\mathrm{Cu}$ positions with half occupation and squares are at Si sites.

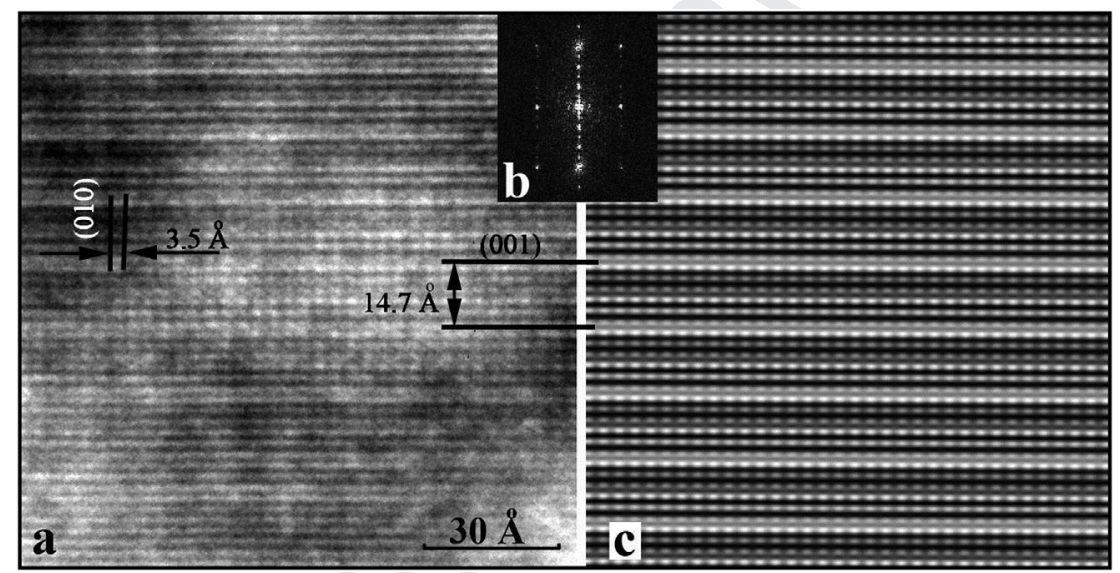

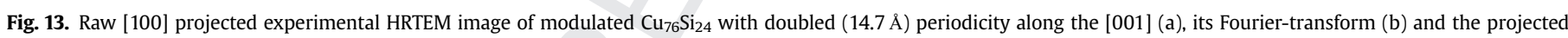
charge density map (c) retrieved by the CRISP package (Calidris, Version 2.1a), using the experimental HRTEM image and amplitudes from the corresponding SAED patterns.

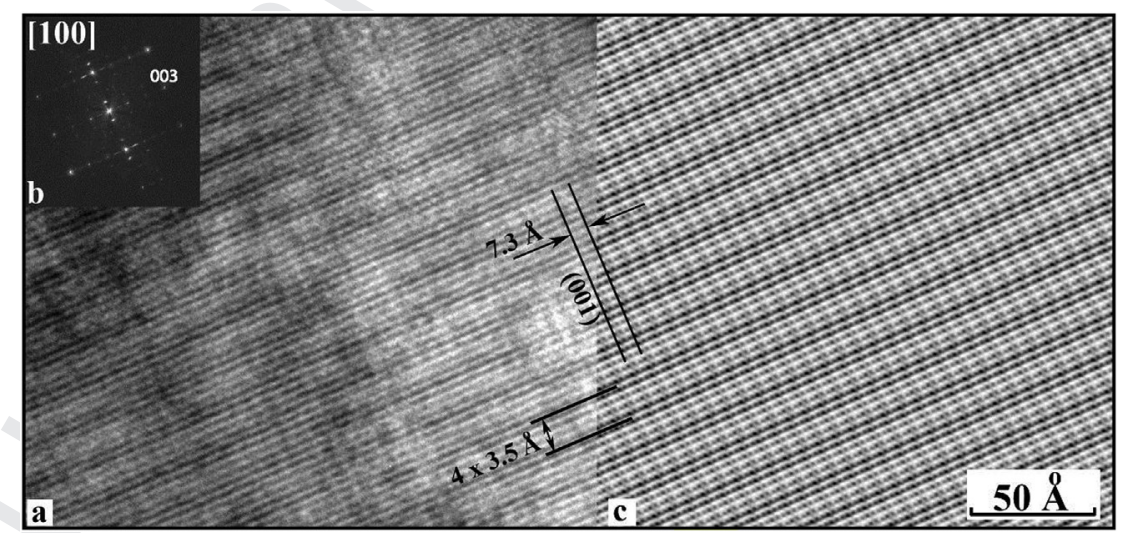

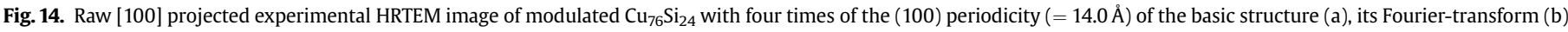
and the Fourier-filtered experimental image (c).

composition. The value of $x$ is slightly increasing in the $\mathrm{Cu}_{3+x} \mathrm{Si}$ formula in the $\eta, \eta^{\prime}, \eta$ " order [20]. Samson and coworkers [21] observed silicon precipitations from the heat treated homogenous " $\eta$ " phase with $\mathrm{Cu}_{0.738} \mathrm{Si}_{0.262}$ composition. They found the first transformation and silicon precipitation on heating, just below $500^{\circ} \mathrm{C}$, and interpreted as the $\eta \rightarrow \eta$ ' reaction. In addition, repeated diffraction patterns (after two days) on the same samples showed different peak positions and intensity values, which means that the structural state changes in time.

In our experiment after the in-situ heating, the sample texture, and the real structure of crystals changed with the elapsed time (within a week). Fig. 15 gives a comparison of the freshly formed 


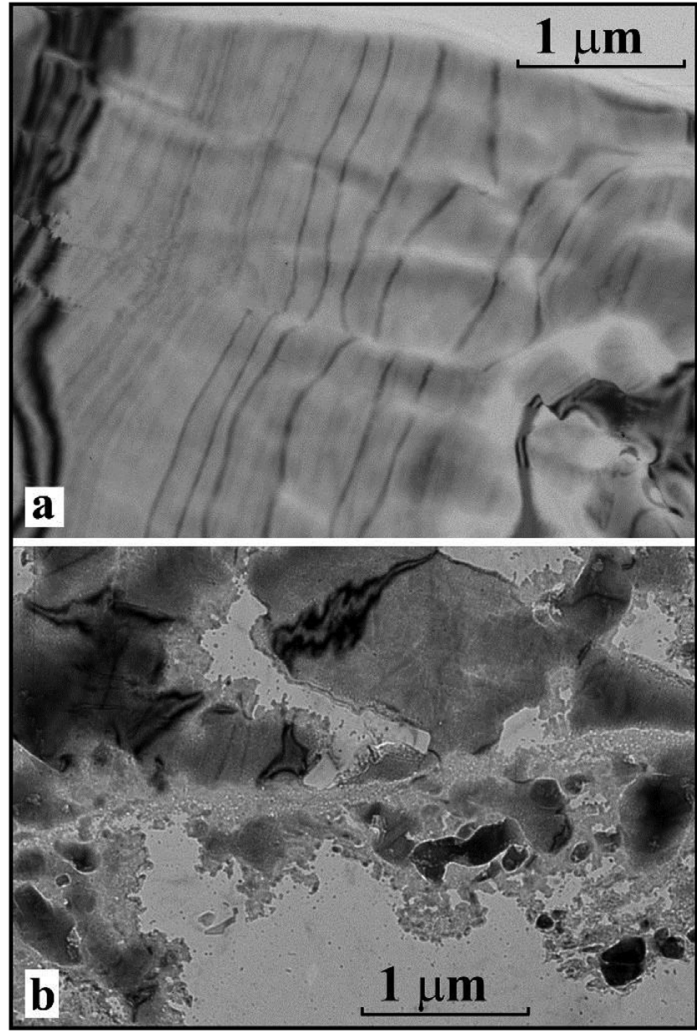

Fig. 15. Two typical bright field TEM images from the same sample. The image in (b) captured one week after (a).

Table 3

Occupancies and atomic coordinates for the $2 x \mathbf{c}$ modulated $\mathrm{Cu}_{3} \mathrm{Si}$.

\begin{tabular}{lllll}
\hline$\#$ & Occupancy & $\mathrm{x}$ & $\mathrm{y}$ & $\mathrm{z}$ \\
\hline 1 & Cu 1.000 & 0.0000 & 0.0000 & 0.0000 \\
2 & Cu 0.500 Si 0.500 & 0.6667 & 0.3333 & 0.0833 \\
3 & Cu 0.500 Si 0.500 & 0.3333 & 0.6667 & 0.0833 \\
4 & Cu 1.000 & 0.0000 & 0.0000 & 0.1667 \\
5 & Cu 0.500 Si 0.500 & 0.3333 & 0.6667 & 0.2500 \\
6 & Cu 0.500 Si 0.500 & 0.6667 & 0.3333 & 0.2500 \\
7 & Cu 1.000 & 0.0000 & 0.0000 & 0.3333 \\
8 & Cu 0.500 Si 0.250 & 0.3333 & 0.6667 & 0.4167 \\
9 & Cu 0.500 Si 0.250 & 0.6667 & 0.3333 & 0.4167 \\
10 & Cu 1.000 & 0.0000 & 0.0000 & 0.5000 \\
11 & Cu 0.500 Si 0.500 & 0.3333 & 0.6667 & 0.5833 \\
12 & Cu 0.500 Si 0.500 & 0.6667 & 0.3333 & 0.5833 \\
13 & Cu 1.000 & 0.0000 & 0.0000 & 0.6667 \\
14 & Cu 0.500 Si 0.250 & 0.3333 & 0.6667 & 0.7500 \\
15 & Cu 0.500 Si 0.250 & 0.6667 & 0.3333 & 0.7500 \\
16 & Cu 1.000 & 0.0000 & 0.0000 & 0.8333 \\
17 & Cu 0.500 & 0.3333 & 0.6667 & 0.9167 \\
18 & Cu 0.500 & 0.6667 & 0.3333 & 0.9167 \\
\hline
\end{tabular}

texture and one week older. These rough changes may be caused by the extreme mobility of copper atoms in silicon. In crystalline silicon copper is by an order of magnitude the fastest element [2] with the diffusivity around $2.8 \times 10^{-7} \mathrm{~cm}^{2} \mathrm{~s}^{-1}$ at room temperature. The high mobility of copper in silicon [22] led to modulated $\mathrm{Cu}_{76} \mathrm{Si}_{24}$ structures. The two superstructures which are detailed in Tables 3 and 4 are products of these time dependent changes. The volume ratio of modulated structures increases with the elapsed time at room temperature. Our results are in accordance with previous observations [21].

We were able to solve the modulated $\eta-\mathrm{Cu}_{3} \mathrm{Si}$ superstructure
Table 4

Occupancies and atomic coordinates for the 4 xa modulated $\mathrm{Cu}_{3} \mathrm{Si}$.

\begin{tabular}{lllll}
\hline$\#$ & Occupancy & $\mathrm{x}$ & $\mathrm{y}$ & $\mathrm{z}$ \\
\hline 1 & Cu 1.000 & 0.0000 & 0.0000 & 0.0000 \\
2 & Cu 1.000 & 0.5000 & 0.0000 & 0.0000 \\
3 & Cu 1.000 & 0.2500 & 0.0000 & 0.0000 \\
4 & Cu 1.000 & 0.7500 & 0.0000 & 0.0000 \\
5 & Cu 0.500 Si 0.375 & 0.0833 & 0.6667 & 0.1667 \\
6 & Cu 0.500 Si 0.375 & 0.4167 & 0.3333 & 0.1667 \\
7 & Cu 0.500 Si 0.375 & 0.1667 & 0.3333 & 0.1667 \\
8 & Cu 0.500 Si 0.375 & 0.3333 & 0.6667 & 0.1667 \\
9 & Cu 0.500 & 0.5833 & 0.6667 & 0.1667 \\
10 & Cu 0.500 & 0.6667 & 0.3333 & 0.1667 \\
11 & Cu 0.500 & 0.9167 & 0.3333 & 0.1667 \\
12 & Cu 1.000 & 0.0000 & 0.0000 & 0.3333 \\
13 & Cu 1.000 & 0.2500 & 0.0000 & 0.3333 \\
14 & Cu 1.000 & 0.5000 & 0.0000 & 0.3333 \\
15 & Cu 1.000 & 0.7500 & 0.0000 & 0.3333 \\
16 & Cu 0.500 Si 0.500 & 0.0833 & 0.6667 & 0.5000 \\
17 & Cu 0.500 Si 0.500 & 0.4167 & 0.3333 & 0.5000 \\
18 & Cu 0.500 Si 0.500 & 0.1667 & 0.3333 & 0.5000 \\
19 & Cu 0.500 Si 0.500 & 0.3333 & 0.6667 & 0.5000 \\
20 & Si 0.500 Cu 0.250 & 0.8333 & 0.6667 & 0.5000 \\
21 & Si 0.500 Cu 0.250 & 0.9167 & 0.3333 & 0.5000 \\
22 & Si 0.500 Cu 0.250 & 0.5833 & 0.6667 & 0.5000 \\
23 & Si 0.500 Cu 0.250 & 0.6667 & 0.3333 & 0.5000 \\
24 & Cu 1.000 & 0.0000 & 0.0000 & 0.6667 \\
25 & Cu 1.000 & 0.7500 & 0.0000 & 0.6667 \\
26 & Cu 1.000 & 0.5000 & 0.0000 & 0.6667 \\
27 & Cu 0.500 & 0.1667 & $0.8333 t$ & 0.6667 \\
28 & Cu 1.000 & 0.2500 & 0.0000 & 0.6667 \\
29 & Cu 0.750 Si 0.250 & 0.0833 & 0.6667 & 0.8333 \\
30 & Cu 0.750 Si 0.250 & 0.1667 & 0.3333 & 0.8333 \\
31 & Cu 0.750 Si 0.250 & 0.3333 & 0.6667 & 0.8333 \\
32 & Cu 0.750 Si 0.250 & 0.4167 & 0.3333 & 0.8333 \\
33 & Cu 0.500 Si 0.375 & 0.5833 & 0.6667 & 0.8333 \\
34 & Cu 0.500 Si 0.375 & 0.6667 & 0.3333 & 0.8333 \\
35 & Cu 0.500 Si 0.375 & 0.8333 & 0.6667 & 0.8333 \\
36 & Cu 0.500 Si 0.375 & 0.9167 & 0.3333 & 0.8333 \\
\hline
\end{tabular}

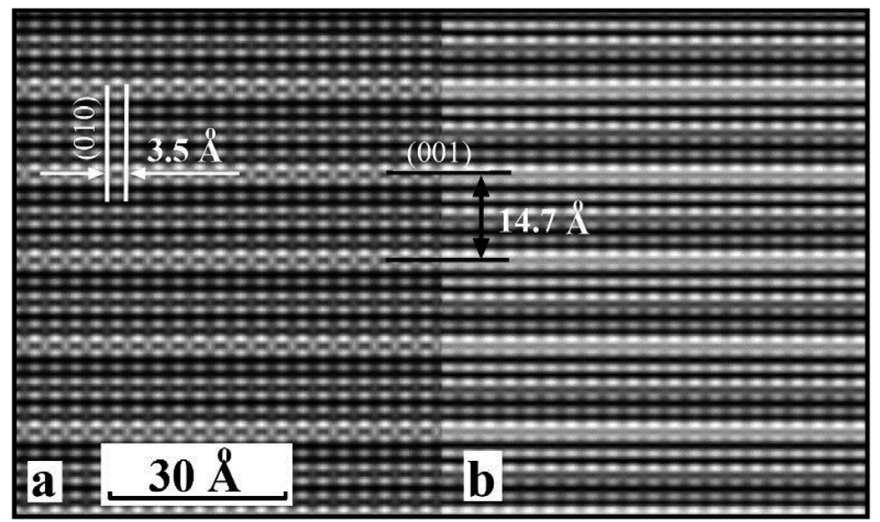

Fig. 16. Simulated HRTEM image (a) using experimental parameters, and structural data listed in Table 3 gives a good match with the filtered experimental HRTEM image (b).

varieties by tuning site occupancies at positions inside supercells built up by multiple unit cells. We measured modulations both along the $\boldsymbol{c}$ and $\boldsymbol{a}$ axes, respectively. The simulated HRTEM image in Fig. 16a using the experimental parameters $\left(300 \mathrm{kV}, 0.6 \mathrm{~mm} \mathrm{c}_{\mathrm{s}}\right.$, $0.3 \mathrm{mrad}$ divergence, $2.08 \AA$ resolution, $81 \AA$ sample thickness and $-300 \AA$ defocus value) and the ordering values listed in Table 2 for doubled $\boldsymbol{c}$ modulation gave an excellent match with the filtered experimental HRTEM image in Fig. 16b (also in Fig. 13c). The period length of modulation along the $\boldsymbol{a}$ axis is typically $4 x d_{(100)}(14 \AA)$. We found satisfactory matches in between the Fourier-filtered
66

67

68

69

70

71

73

74

75

76

77

78

79

80

81

82

83

84

85

86

87

88

89

90

91

92

93

94

95

96

97

98

99

101

102

103

104

105

106
107

108

109
110

111

112

113

114

115
116

117

118

119

120

121

122
123

124

125

126

127

128

130 


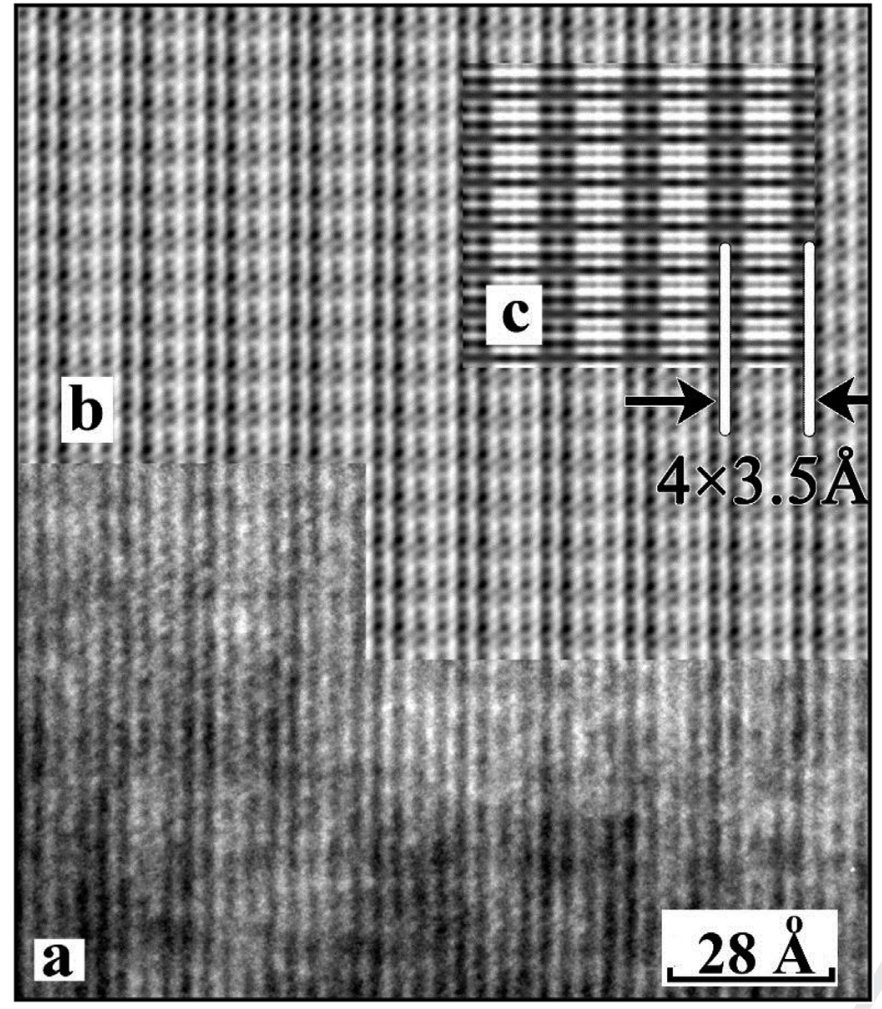

Fig. 17. Raw HRTEM image (a) and Fourier-filtered experimental HRTEM image (b) gives a good match with the simulated HRTEM image (c) using experimental parameters and structural data listed in Table 4.

experimental HRTEM (in Fig.17b) and a simulated ( $300 \mathrm{kV}, 0.6 \mathrm{~mm}$ $c_{s}, 0.6 \mathrm{mrad}$ divergence, $2.08 \AA$ resolution, $81 \AA$ sample thickness and $-400 \AA$ (extended-Scherzer) defocus value) image, based on the atomic coordinates and site occupancies listed in Table 4.

\section{Conclusion}

We heat treated copper grids contacted with $10 \mathrm{~nm}$ thick amorphous Si layer at $500^{\circ} \mathrm{C}$ and determined the phases and structures formed using transmission electron microscopy and electron crystallography. A new structural model was constructed for $\mathrm{Cu}_{3} \mathrm{Si}-\eta$ phase $\left(\mathrm{Cu}_{76} \mathrm{Si}_{24}\right)$ in order to get a fit with the experimental HRTEM images and SAED patterns. The time dependent appearance of modulated superstructures was attributed to the extreme mobility of $\mathrm{Cu}$ atoms in $\mathrm{Si}$. Two modulated $\mathrm{Cu}_{3} \mathrm{Si}$ structures were solved by tuning the site occupancies in the supercell, to give satisfactory matches between the models and the experimental data.

In contrast to the majority of published papers on the phase relations [4-6,21-25], our experiment on copper-silicides was produced by heating copper and amorphous silicon, in high vacuum. It seems to be evident that no $\mathrm{Cu}_{79} \mathrm{Si}_{21}(\varepsilon)$ phase [26] formed up to $500{ }^{\circ} \mathrm{C}$. Combined with the knowledge of the previously mentioned works like Riani et al.'s [6], this prompts the question whether a new comprehensive study of the $\mathrm{Cu}-\mathrm{Si}$ phase diagram is needed.

\section{Acknowledgements}

This work was supported in the frame of a Hungarian-Greek bilateral scientific collaboration (Project Codes TET-10-0-2011-
0570 for Hungary and HUN92 for Greece). The authors would like to thank gratefully János L. Lábár for valuable comments during manuscript preparation.

\section{References}

[1] S. Pizzini, Solar grade silicon versus electronic grade silicon for photovoltaic applications, J. Power Sources 11 (1984) 115-118.

[2] A. Mitrašinovič, Characterization of the Cu-Si System and Utilization of Metallurgical Techniques in Silicon Refining for Solar Cell Applications, University of Toronto, 2010, pp. 2-217. Doctor of Philosophy Department of Materials Science and Engineering

[3] B.D. Polat, O.L. Eryilmaz, O. Keleş, A. Erdemir, K. Amine, Compositionally graded SiCu thin film anode by magnetron sputtering for lithium ion battery, Thin Solid Films 596 (2015) 190-197.

[4] R.W. Olesinski, G.J. Abbaschian, Bull. Alloy Phase Diagrams 7 (1986) 170-178

[5] S. Cui, I.-H. Jung, Thermodynamic modeling of the quaternary Al-Cu-Mg-Si system, Calphad Comput. Coupling Phase Diagrams Thermochem. 57 (2017) $1-27$.

[6] P. Riani, K. Sufryd, G. Cacciamani, About the $\mathrm{Al}-\mathrm{Cu}-\mathrm{Si}$ isothermal section at $500{ }^{\circ} \mathrm{C}$ and the stability of the $\varepsilon$-Cu15Si4 phase, Intermetallics 17 (2009) $154-164$.

[7] S. Fagerberg, A. Westgren, Ueber den Kristallbau des beta-Mangans und isomorpher Legierungen, Metallwirtschaft 14 (1935) 265-267.

[8] J.K. Solberg, The crystal structure of $\eta$-Cu3Si precipitates in silicon, Acta Crystallogr. A34 (1978) 684-698.

[9] N. Mattern, B. Schüpp, C. Bähtz, Crystal Structure and Phase Transformation of Cu3Si, 2001. http://hasyweb.desy.de/science/annual_reports/2001_report/ part1/contrib/44/4839.pdf.

[10] N. Mattern, R. Seyrich, L. Wilde, C. Baehtz, M. Knapp, J. Acker, Phase formation of rapidly quenched $\mathrm{Cu}-\mathrm{Si}$ alloys, J. Alloy. Comp. 429 (2007) 211-215.

[11] C.Y. Wen, F. Spaepen, In situ electron microscopy of the phases of $\mathrm{Cu}_{3} \mathrm{Si}$, Phil. Mag. 87 (34) (2007) 5581-5599.

[12] C.A. Corrêa, P. Morgane, J. Kopeček, R. Král, P. Zemenová, J. Lecourt, N. Barrier, P. Brázda, M. Klementová, L. Palatinus, Phase transitions of $\mathrm{Cu}_{3+\mathrm{x}} \mathrm{Si}$ observed by temperature-dependent X-ray powder diffraction, Intermetallics 91 (2017) 129-139.

[13] L. Palatinus, M. Klementová, V. Dřínek, M. Jarošová, V. Petříček, An incommensurately modulated structure of $\eta$ '-phase of $\mathrm{Cu}_{3+\mathrm{x}} \mathrm{Si}$ determined by quantitative electron diffraction tomography, Inorg. Chem. 50 (2011) 3743-3751.

[14] L. Palatinus, G.J. Chapuis, SUPERFLIP - a computer program for the solution of crystal structures by charge flipping in arbitrary dimensions, Appl. Crystallogr. 40 (2007) 786-790

[15] V. Petříček, M. Dušek, L. Palatinus, The Crystallographic Computing System JANA2006, Institute of Physics, Praha, Czech Republic, 2006.

[16] Inorganic Crystal Structure Data Base, FIZ Karlsruhe.

[17] J.M. Cowley, in: J.M. Cowley (Ed.), Electron Diffraction Techniques, vol. 1, Oxford Univ.Press, Oxford, 1992.

[18] X. Zou, S. Hovmöller, P. Oleynikov, Electron Crystallography: Electron Microscopy and Electron Diffraction, OUP Oxford, 2011.

[19] M. Re, E. Carlino, L. Sorba, A. Francios, B.H. Müller, High resolution transmission electron microscopy to study very thin crystalline layers buried at an amorphous-crystalline interface, Micron 31 (2000) 237-243.

[20] B. Hallstedt, J. Gröbner, M. Hampl, R. Schmid-Fetzer, Calorimetric measurements and assessment of the binary $\mathrm{Cu}-\mathrm{Si}$ and ternary $\mathrm{Al}-\mathrm{Cu}-\mathrm{Si}$ phase diagrams, Calphad Comput. Coupling Phase Diagrams Thermochem. 53 (2016) 25-38.

[21] Y. Samson, J.L. Rousset, G. Bergeret, B. Tardy, J.G. Bertolini, G. Laroze, On the surface segregation of silicon in $\mathrm{Cu}_{3} \mathrm{Si}$, Appl. Surf. Sci. 72 (1993) 373-379.

[22] S.B. Lee, D.-K. Choi, F. Phillipp, K.-S. Jeon, C.K. Kim, In situ high-resolution transmission electron microscopy study of interfacial reactions of $\mathrm{Cu}$ thin films on amorphous silicon, Appl. Phys. Lett. 88 (2006), 083117/1-3.

[23] D. Shin, J.E. Saal, Z.-K. Liu, Thermodynamic modeling of the $\mathrm{Cu}-\mathrm{Si}$ system, Computer Coupling of Phase Diagrams and Thermochemistry 32 (2008) 520-526.

[24] Y. Song, X. Su, Y. Liu, H. Peng, Ch Wu, J. Wan, Phase equilibria of the Cu-Si-Sn system at 700 and $500{ }^{\circ} \mathrm{C}$, J. Phase Equilibria Diffusion 36 (5) (2015) 493-502.

[25] E.M. Shpilevsky, M.E. Shpilevsky, M.A. Andreev, Change in the phase growth rates in $\mathrm{Cu}-\mathrm{Si}$ films subjected to ion implantation, Surf. Coating. Technol 74-75 (1995) 937-940.

[26] K.P. Mukherjee, J. Bandyopadhyaya, K.P. Gupta, Phase relationship and crysta structure of intermediate phases in the $\mathrm{Cu}$-Si system in the composition range of 17 to 25 at. \% Si, Transactions of the Metallurgical Society of Aime 245 (1969) 2335-2338.

[27] J.H. Foley, G.V. Raynor, Lattice spacings in the system Cu-Ge-Si, Trans. Faraday Soc. 57 (1961) 51-60.

[28] Y.P. Xie, S.J. Zhao, The energetic and structural properties of bcc $\mathrm{Ni} \mathrm{Cu}, \mathrm{Fe} \mathrm{Cu}$ alloys: a first-principles study, Comput. Mater. Sci. 50 (2011) 2586-2591.

[29] F. Jona, P.M. Marcus, Structural properties of copper, physical review, Serie 3. B - Condensed Matter 63 (9) (2001), 094113-1-094113-8. 